\title{
Ciència i ciutadania: el Projecte APQUA
}

\author{
Imma Ros \\ iros1@pie.xtec.es
}

APQUA és un projecte de culturització científica dirigida a tota la població, centrat en els productes $i$ els processos químics i en el risc que el seu ús representa per a les persones $i$ per al medi ambient.

APQUA (Aprenentatge de Productes Químics, els seus Usos i Aplicacions) vol aconseguir que els alumnes adquireixin nous i suficients coneixements, i despertar el seu interès en les qüestions relacionades amb l'activitat humana, que els ajudi a analitzar les diferents concepcions científiques situant-les en el context cultural i ideològic on varen sorgir i, al mateix temps, tenir present, en el currículum, la dimensió ecològica i els valors humans (polítics, morals, estètics...)

És un projecte que té en compte l'educació per la ciutadania.

El projecte APQUA a Catalunya és el resultat de la col-laboració entre el Departament d'Enginyeria Química de la URV (Universitat Rovira i Virgili) i el programa SEPUP http://www.sepuplhs.org (Science Education for Public Understanding Program) del Lawrence Hall of Science de la Universitat de Califòrnia a Berkeley.

\section{OBJ ECTIUS: APRENDRE A PRENDRE DECISIONS}

- Aconseguir que les persones aprenguin a obtenir informació sobre tot allò que els preocupa en relació amb la ciència del seu entorn.

- Desenvolupar una major consciència, un coneixement i una comprensió publica més gran dels productes químics i de com aquests interaccionen amb les nostres vides.

- Promoure l'ús de principis i processos científics, i de l'evidència en la presa de decisions.

- Subministrar a les persones els coneixements i les eines necessàries perquè puguin prendre les seves pròpies decisions i participar d'una forma més efectiva com a membres d'una societat lliure i democràtica.

\section{METODOLOGIA: LA INFORMACIÓ HA DE SABER-SE UTILITZAR}

Donar informació sobre els continguts de la matèria lligada a un conjunt d'experiències, experimentals o simulades, a uns textos que es corresponguin amb els continguts curriculars i realitzar diferents seqüències de pràctiques de laboratori o treballs de recollida de dades.

"Si la informació no sap utilitzar-se per a prendre decisions, serveix de molt poc. Informar no vol dir educar"

\section{MATERIALS}

Estan dissenyats per utilitzar-se a l'aula amb la màxima seguretat $\mathrm{i}$ poder experimentar les tècniques bàsiques de laboratori.

El projecte s'estructura en mòduls i aporta el material següent:

- Guia del professor

- Guia de l'alumne

- Caixa amb material específic

- Safates per realitzar els experiments, ampolles gotejadores, comptagotes, agitadors, embuts de plàstic, etc. 


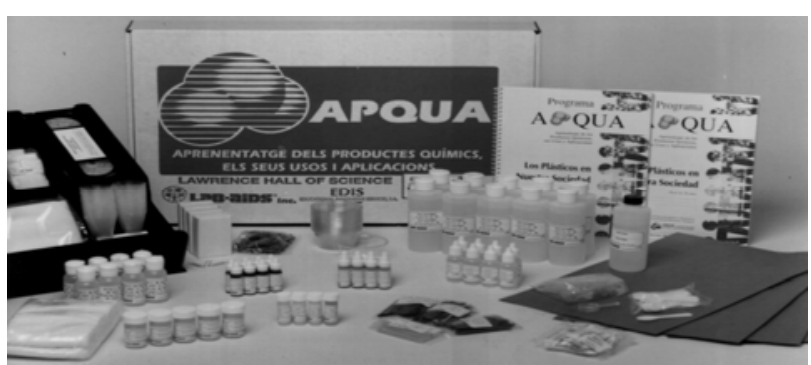

Les guies estan editades en català, castellà, euskera, anglès...

\section{PROGRAMA ESCOLAR}

El programa escolar pretén que els alumnes es qüestionin les seves idees sobre els productes químics, sobre el medi que els rodeja, i sobre els serveis i aplicacions que els dóna la societat.

És un projecte educatiu que creu que estar ben informat és necessari per a poder prendre decisions d'una forma responsable en la formulació de qualsevol política relacionada amb la ciència

APQUA creu que l'aprenentatge de les ciències a l'aula no significa sols llegir un llibre sinó realitzar activitats, preguntes, discussions i involucrar-se en debats. Per això utilitza la simulació d'una història que planteja una situació problemàtica i d'actualitat en la qual la ciència els mostri l'evidència del problema però en la que les decisions per a pal-liar-lo poden ser diveses.

La introducció del projecte APQUA en el currículum de l'alumne aporta una nova metodologia: treballar per projectes.

Les activitats de treball plantegen preguntes obertes i situacions simulades de temes d'actualitat. L'alumne s'adona que els temes de ciències i tecnologia son qüestions sobre les que les persones prenen decisions com a membres d'una societat lliure i democràtica.

\section{MÒDULS D'APQUA: EL TREBALL PER PROJ ECTES}

Estan formats per diverses activitats de treball, en les quals s'ofereixen situacions simulades, es plantegen preguntes obertes, i es realitzen experiments.

Els mòduls no són un conjunt de pràctiques deslligades, sinó una forma d'ensenyar a plantejar i resoldre problemes que interessen a la societat actual mitjançant un eix conductor.

Amb ells s'ensenyen els continguts científics, els processos i les habilitats de resolució de problemes perquè els alumnes puguin prendre decisions personals.
No es pretén que l'estudiant sigui un activista d'una causa determinada o prengui una posició concreta davant d'un problema social, sinó que desenvolupi la seva capacitat de comprensió i crítica sobre temes científics i sobre les limitacions de la ciència.

Els diferents mòduls que actualment formen el programa escolar adreçat a l'Educació Secundària Obligatòria (ESO) estan agrupats en dos grans blocs, encara que aquests poden treballar-se independentment o acompanyar una seqüenciació més àmplia d'un tema.

\section{Primer bloc}

Investigació del que entenen els alumnes per "producte químic" per posteriorment tractar dues situacions diferents de contaminació d'aigua (superficial per àcids i aqüífers per pesticides):

- Els productes químics

- Dissolucions i contaminació

- Un joc de rol: Contaminació de I' aigua subterrània del poble de "Vallfrondosa"

\section{Segon bloc}

Planteja inicialment el concepte de "risc" a partir de situacions de la vida quotidiana: possible toxicitat d' un additiu alimentari, tractament de residus de metalls pesats en una solució residual d'una empresa de galvanotècnia, i com han de tractar-se els diferents residus que genera la societat.

- Risc: el joc de la vida

- Toxicologia. Determinació de valors llindar

- Tractament de residus especials

- La gestió de residus

\section{DISTRIBUCIÓ DELS MÒDULS \\ EN EL CURRÍCULUM DE SECUNDÀRIA OBLIGATÒRIA}

\section{Primer cicle d'ESO}

\section{Ciència integrada}

- Productes químics (enquestes)

- Vallfrondosa (joc de rol)

- Dissolucions i contaminació (més acadèmic)

- Plàstics (part qualitativa)

\section{Segon cicle d'ESO}

\section{Biologia \\ - Toxicologia: El valor llindar \\ Química \\ - Tractament de residus especials}




\section{- Gestió de residus}

\section{Química/Tecnologia}

- Els plàstics en la nostra societat

Descriurem, com a exemple, un mòdul en el qual es treballa els concepte d'ió, electròlit, canvi químic, tipus de reaccions, pluja àcida...

\section{EL TRACTAMENT DELS RESIDUS ESPECIALS}

Es tracta d'un mòdul recomanat per a segon cicle d'ESO, amb una durada d'unes 30 hores.

La seva filosofia és la del "mètode del cas". Amb ell s'estudiaran les diferents alternatives entre les quals els alumnes hauran de prendre una decisió per fer front a un problema ecològic. (D'alguna forma podríem incitar els alumnes a recollir informació sobre el desastre d'Aznalcóllar, el Prestige...).

Els alumnes hauran de:

- Estudiar el procés tecnocientífic, i no el procés tancat que presenta els resultats com si fossin naturals (lineals, lògics, objectius i evidents)

- Entendre i comprendre les interpel-lacions entre ciència - tecnologia - societat i educació en valors.

- Desenvolupar el sentit de responsabilitat paral-lelament a la seva formació com a ciutadans, perquè siguin capaços de comprendre fenòmens complexos, reflexionar i elaborar judicis de valor propis, formular-se preguntes que representin un paper decisiu en la societat i que representin una repercussió important sobre els drets fonamentals i les llibertats individuals, al mateix temps que els estimula a aprendre a prendre decisions i a participar activament en la vida social.

Introdueix el tema plantejant els nostres dubtes de com la societat pren les decisions.

Plantejarem el "cas" de manera que els alumnes assumeixen el paper d'enginyers d'una consultora mediambiental a la qual se li planteja la necessitat de decidir quina és la millor manera de tractar una solució residual que conté coure, generada pel tancament d'una empresa de galvanotècnia.

Compararem els possibles mètodes de neteja del residu per dissolució, substitució, precipitació i inertizació, tenint en compte no sols la seva efectivitat sinó també el cost i l'impacte ambiental.

1) Utilitzen la solució de clorur de coure (II) per recobrir un clip de níquel i se'ls planteja el problema del tractament de la solució usada que conté un metall tòxic.

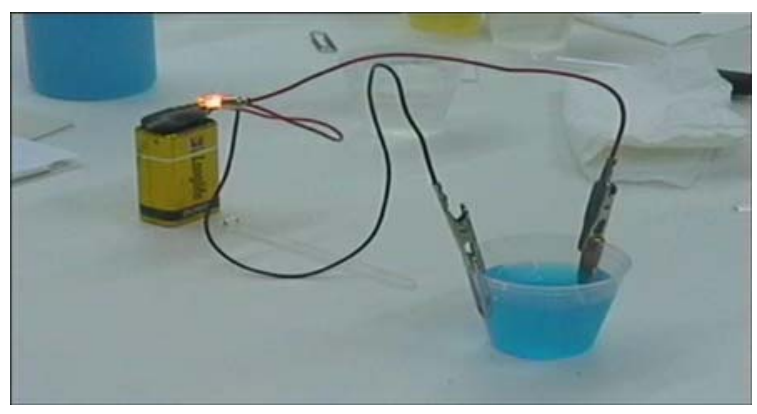

2) Determinen el volum d'aigua necessari per dissoldre una quantitat determinada de la solució residual de clorur de coure (II), tenint en compte la normativa sobre aigües d' una hipotètica localitat. Realitzen un test per determinar la presencia d'ions de coure en solució.

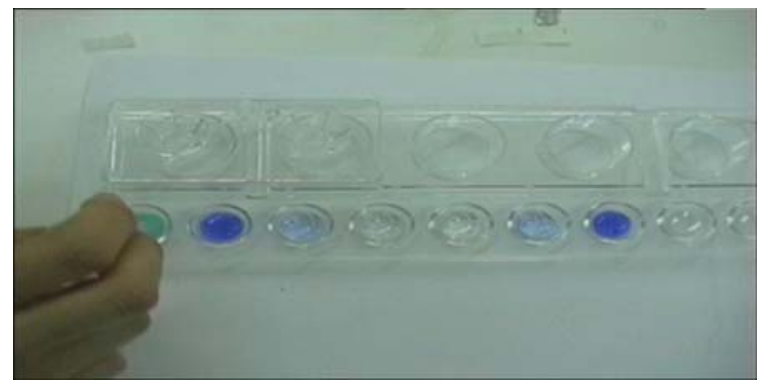

3) Investiguen l'ús de l'alumini com a mètode per recuperar coure. Realitzen una reacció de substitució.

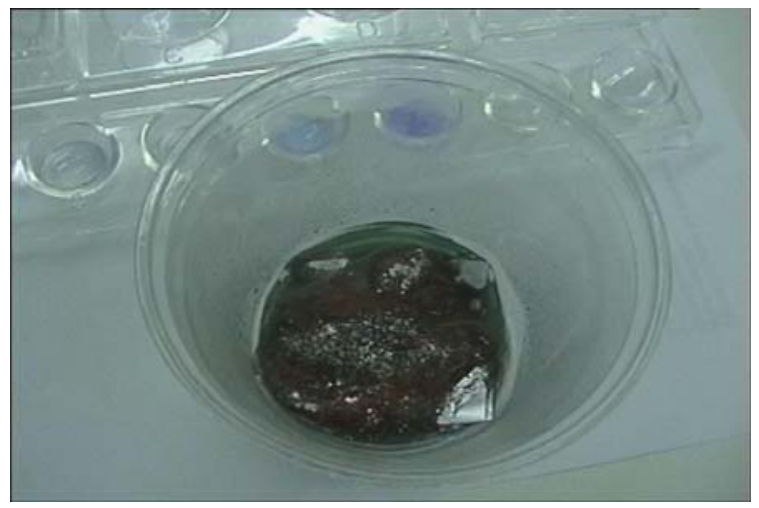

4) Investiguen si altres metalls (ferro, zinc...) recuperaren el coure tal com ho ha fet l'alumini i determinen quin d'ells és el més efectiu considerant el cost econòmic i la toxicitat de cadascun d'ells per decidir quin és el més adequat.

5) Observen i separen el precipitat sòlid que es produeix al barrejar la solució residual de clorur de coure (II) amb altres solucions (en aquest cas fosfats i carbonats de sodi). Determinen quina de les reaccions de precipitació és la més efectiva per eliminar els ions coure. 
6) Posteriorment, simulen els efectes de la "pluja àcida" sobre els precipitats dipositats en un abocador imaginari.

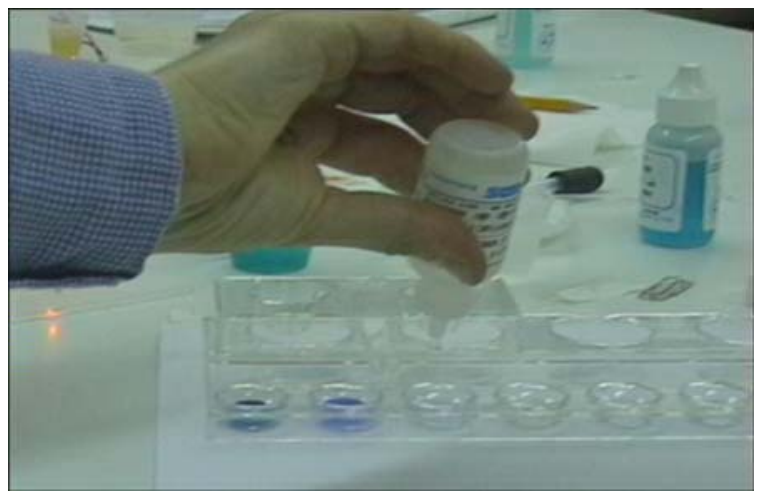

7) Realitzen la inertització dels ions coure amb ciment Portland i silicat de sodi. Investiguen el grau de lixiviació dels ions coure provocats per una pluja àcida imaginaria.

8) Amb la ajuda d'una taula de doble entrada comparen avantatges i inconvenients de cadascun dels mètodes estudiats en relació amb la destinació final del residu, la facilitat de realització del procés, el cost i les preguntes generals relacionades amb el medi.

9) Prenen una decisió

\section{Treballar amb TASQUES}

APQUA té també un programa adreçat al cicle superior de Primària, però que també pot adreçarse (actualment s'està fent en diferents centres) als alumnes que es troben en aules en les quals el ritme d'aprenentatge dels alumnes és molt divers.

Són unitats de treball més curtes formades per un conjunt de sols 2 o 3 activitats, amb la mateixa metodologia dels mòduls.

- Dóna molta importància a l'experimentació

- Tots els experiments poden realitzar-se a l'aula

- S'utilitzen materials senzills que habitualment hi ha a casa

- Proporciona activitats d'ensenyament- aprenentatge per tal que els alumnes realitzin un aprenentatge significatiu i que els professors facin una ciència basada en l'experiència com a part habitual del seu programa educatiu sobre la salut

- Se suggereixen activitats de ciències socials $\mathrm{i}$ llengua relacionades amb el tema tractat.

Igual que els mòduls, les TASQUES poden agrupar-se en tres blocs sota un mateix fil conductor, encara que son independents entre elles:

\section{1r d'ESO}

- Ecosistemes i medi ambient. Hi ha química a les nostres vides?

- Bona fins a l'última gota!

- $\mathrm{CO}_{2}$ i vida

- El vessament misteriós

- Massa brossa

\section{2n d'ESO}

- Energia per funcionar

- Hi ha química a les nostres vides?

- El so

- Energia per funcionar!

- Una casa més segura

- Noticies

\section{3r d'ESO}

- Els hàbits i la salut

- Què és un valor llindar?

- Què "porten els aliments"?

- Com actuen els medicaments?

- M'encanta el dolç

- L'aventura de fumar

APQUA no considera a l'alumne com un consumidor passiu de la informació, sinó al contrari. Les estratègies educatives que utilitza presenten una clara visió constructivista de l'aprenentatge, encara que no és estricta sinó flexible, contextual $\mathrm{i}$ funcional:

- El protagonista és l'alumne.

- El professor és el facilitador del coneixement.

- APQUA planteja preguntes.

- L'alumne obté evidències i pren decisions

\section{Podem dir que APQUA tracta:}

\section{Continguts}

- Efectes dels productes químics sobre els sistemes vius

- Propietats i interaccions dels materials en el nostre entorn

\section{Competències generals}

- Interaccions socials: Discussió, comunicació, cooperació...

- Presa de decisions socials basades en evidències

- Valorar els avantatges, inconvenients, concessions...

- Importància social i personal de la ciència 


\section{Estratègies}

- Procediments experimentals: disseny d'experiments...

- Mesura i anàlisi de dades: observació, obtenció de dades, enquestes, tabulació...

- Avaluació del risc: estimació, càlcul....

\section{Programa de visites educatives}

El Programa de Visites Educatives (PVE) a indústries planteja l'aprenentatge de continguts curriculars en el marc de la indústria, a partir de les activitats del Programa Escolar.

Els objectius de les visites educatives a indústries són:

- Treballar alguns dels continguts curriculars de l'Educació Primària i Secundària en el context d'una visita a una indústria.

- Donar a conèixer als joves les oportunitats professionals en la indústria i promoure l'interès i la motivació per la ciència i la tecnologia.

- Permetre la creació d'una opinió fonamentada en l'experiència personal sobre qüestions de seguretat, salut laboral, protecció del medi ambient, etc., relacionats amb la indústria.

- Contribuir a la creació de relacions de cooperació i coneixement mutu entre els centres educatius i les indústries

\section{Impacte del Projecte}

Des de l'any 1989 fins al 2003, més de 173.000 alumnes de 1.110 centres d'ensenyament primari i secundari, han utilitzat els mòduls d'APQUA.

En aquest període s'han realitzat 178 cursos de formació amb una assistència total de 3.685 docents.

\section{Com contactar amb APQUA?}

Universitat Rovira i Virgili, Facultat de Ciències de l'Educació i Psicologia Carretera de Valls, s/n (Zona Educacional) 43007 TARRAGONA

Tels: 977558058 - 558178

Fax: 977558059

apqua@astor.urv.es

www.etseq.urv.es/apqua

Magda Medir, directora d'APQUA

Barbara Nagle, directora de SEPUP i assessora d'APQUA

Herbert $D$. Thier, director fundador de SEPUP i assessor d'APQUA

\section{Materials d'APQUA en servei de prèstec}

Centre de Documentació i Experimentació de Ciències i Tecnologia (CDECT)

Passeig de la Vall d'Hebron, 64-70

08023 Barcelona

Telèfon: 934176770

FAX: 934176973

http://www.xtec.es/cdec/

I a les seves subseus de:

- Manresa: CdA del Bages

- Cornellà: CRP Baix Llobregat V

- Girona : CRP del Gironès

- Lleida: CRP del Segrià

- Tarragona: IES Pere Martell

- Tortosa: IES Joaquim Bau

A diversos Centres de Recursos Pedagògics de Catalunya també tenen alguns d'aquests materials en servei de préstec. 